\title{
Analysis of the Adult Traumatic Brain Injury Patients, Experiences of Neurosurgery and Intensive Care Unit
}

\author{
Mustafa Efendioğlu1, Serap Adana Kavlak², Asu Özgültekin² \\ ${ }^{1}$ Department of Neurosurgery, University of Health Sciences, Hamidiye Faculty of Medicine, Haydarpasa Numune Health Application \\ and Research Center, Istanbul, Turkey \\ ${ }^{2}$ Department of Anaesthesiology and Reanimation, University of Health Sciences, Hamidiye Faculty of Medicine, Haydarpasa \\ Numune Health Application and Research Center, Istanbul, Turkey
}

\begin{abstract}
Introduction: Traumatic brain injuries and intracranial bleeding are the most severe forms of traumatic injuries with a high probability of devastating prognosis. Secondary injuries of the brain, following the primary injury, are preventable, and transportation to and in the hospital; the interventions in the emergency department, operational procedures and intensive care (ICU) stay are all crucial for the prevention of the secondary insult to the injured brain. In this retrospective cohort study, we analyzed the traumatic brain injuries that were followed by the neurosurgical and intensive care departments together in ICU for the last two years.

Methods: With the written permission of the hospital administration, the data in the Hospital Information System were examined. Fifty-six patients admitted to the ICU with the diagnosis of traumatic intracranial bleeding over the age of 18 were analyzed. GCS scores on admission and discharge from ICU were regarded as $\geq 8$ (Good outcome) and <8 (Bad outcome), and patients' clinical measures were examined according to these groups.

Results: Pupillary reflexes showed a statistically significant difference between the $\geq 8$ and $<8$ patients on admission. Blood glucose levels were clinically higher in the GCS $<8$ group. On the analysis of the 17 patients whose GCS scores $<8$ (Bad outcome) on discharge, it was seen that 8 of them had GCS scores below 8 on admission. These patients had severe head trauma, multiple intracranial pathologies and underwent decompressive surgery besides the polytrauma of the whole body. Discussion and Conclusion: We found that patients who had polytrauma with high intracranial pressure that could not be controlled with the first-line therapies and undergoing decompressive surgery, and also the patients who had high glucose levels on admission ( $>200 \mathrm{mg} / \mathrm{dl}$ ) showed worse prognosis. Hospitals should have an algorithmic approach and periodic analysis of the performances to prevent those delicate patients from having secondary insults to the brain during the emergency interventions and after.
\end{abstract}

Keywords: Analysis; head injury; intracranial bleeding; therapy.

In addition to being the cause of one out of every ten deaths in the world, trauma is a major cause of disability and serious economic loss, especially in developing countries because trauma affects the younger population severely. According to the World Health Or- ganization, the incidence of trauma-related diseases is expected to increase from $14 \%$ to $20 \%$ in $2020^{[1]}$. Head injuries and intracranial hemorrhages are among the most severe forms of trauma and are likely to cause serious injuries.

Correspondence (Illetişim): Asu Özgültekin, M.D. Saglik Bilimleri Universitesi Hamidiye Tip Fakultesi, Haydarpasa Numune Saglik Uygulama ve Arastirma Merkezi, Anesteziyoloji ve Reanimasyon Klinigi, Istanbul, Turkey

Phone (Telefon): +90 5323434198 E-mail (E-posta): asuozgultekin@yahoo.com

Submitted Date (Başvuru Tarihi): 20.01.2020 Accepted Date (Kabul Tarihi): 21.01.2020

Copyright 2020 Haydarpaşa Numune Medical Journal

OPEN ACCESS This is an open access article under the CC BY-NC license (http://creativecommons.org/licenses/by-nc/4.0/) 
On the development of secondary damage following primary damage of the trauma, as well as risk factors related to the patient, transport, emergency services, operation processes and intensive care treatments play an active role. The necessary follow-up, monitoring, and treatment for a moderate head-injury should also be administered with the attentive approach of a severe head injury; any trauma may progress to a severe and difficult-to-treat form ${ }^{[2]}$. It is the kind of circumstance that every hospital must review within its own operation to determine high-risk groups, to examine these factors to improve the results and to take necessary measures to protect the brain from secondary damage that might have been prevented. The Glasgow Coma Scale remains valid for a rapid assessment in the early period in distinguishing mild or severe head injuries ${ }^{[3]}$.

As the neurosurgery and intensive care clinics of our hospital, in this study, we aimed to evaluate our patients according to their Glasgow Coma Scale (GCS) scores during their intensive care process, onset and termination by conducting a retrospective analysis of the traumatic intracranial hemorrhages that we followed upon for the last two years.

\section{Materials and Methods}

With the written approval of the hospital management, the hospital information system (HIS) records were examined, and patients over the age of 18, who were admitted to the Intensive Care Clinic with the diagnosis of traumatic intracranial bleeding, were analyzed retrospectively in this study. The data of 56 emergency and intensive care patients were evaluated.

Our hospital's approach to head trauma-polytrauma patients includes a standard approach that begins with emergency admission. In our hospital, trauma patients are evaluated according to the triage of the emergency clinic, and the first interventions are made, if necessary, the process is advanced with neurological, respiratory and hemodynamic evaluation, stabilization, emergency imaging and consultation of the appropriate units. In case of an urgent need for operative intervention, the plan is to follow up and treat severe polytrauma-head trauma cases by taking the patient from the emergency unit to the emergency operating room, and from there to intensive care under sedation and mechanical ventilation. The process in intensive care continues with regular follow-ups of the relevant clinics, especially neurosurgery, and in the follow-up of intensive care physicians, and treatment and interventions are planned jointly.

In addition to the demographic data of the patients, their comorbidities, trauma shape, occurrence of polytrauma, neurological examination (Glasgow Coma Scale-GCS) upon arrival, hemodynamic data, peripheral oxygen saturation, hyper-hypoglycemia upon arrival, computed brain tomography findings (CT), whether it was operated, use of steroid-mannitol-antiepileptic, the length of hospitalization, tracheotomy, and the GCS score upon intensive care exit were evaluated, and the length of hospitalization, outcome, and the cause of death were also recorded. GCS arrival and exit scores were evaluated in two groups as $<8$ (expectation of a bad outcome) and $\geq 8$ (expectation of a good outcome).

\section{Statistical Reviews}

When evaluating the findings obtained in this study, IBM SPSS Statistics 22 for statistical analysis (SPSS IBM, Turkey) program was used. The suitability of the parameters to normal distribution was evaluated using the Shapiro Wilks test and it was concluded to be suitable for normal distribution. In addition to the descriptive statistical methods (Average, Standard deviation, frequency), Student's t-test was used to compare quantitative data. In the comparison of qualitative data, Fisher's Exact Chi-Square test, Fisher Freeman Halton Test, Continuity (Yates) Correction and Pearson correlation analysis were used to examine the relationships between parameters. Significance was evaluated at the level of $p<0.05$.

\section{Results}

This study was conducted on 51 cases, 40 (78.4\%) male and 11 (21.6\%) female, aged between 19 and 93, with five cases with incomplete records taken out. The average age of the cases was 66.1 \pm 19.4 (median 71).

The average of arrival to the emergency GCS was $10.9 \pm 4.3$ (median 13). The intensive care hospitalization period ranged from 0 to 74 days, with an average of $12.7 \pm 17.3$ (median 5) days. Of the 11 patients with arrival GCS $<8,4$ were hospitalized six days or less, and seven were hospitalized 10 days or more.

The intensive care unit exit GCS score ranged from 6 to 15, with an average of $9.7 \pm 3.5$ (median 7 ). Intensive care arrival and exit GCS score distributions are summarized in Table 1. While the number of patients with GCS $\geq 8$ at the intensive care unit was 35 , it is seen that the number of patients in this group at the time of exit decreased to 22. In the patient groups examined, the causes of head trauma were determined as non-vehicle (NVTA) and in-vehicle (IVTA) traffic accidents and falls (Table 2 ). 
Table 1. GCS score distributions

\begin{tabular}{lll}
\hline & $\mathbf{n}$ & $\%$ \\
\hline $\begin{array}{l}\text { GCS-Arrival } \\
\geq 8\end{array}$ & 35 & 68.6 \\
$<8$ & 16 & 31.4 \\
GCS-Exit & & \\
$\geq 8$ & 22 & 43.1 \\
$<8$ & 29 & 56.9 \\
\hline
\end{tabular}

Table 2. Evaluation of the GCS score input according to trauma types

\begin{tabular}{lcccc}
\hline Trauma Type & \multicolumn{3}{c}{ GCS-Arrival } & p \\
\cline { 2 - 4 } & $\begin{array}{lccc}\geq \mathbf{8} \\
\mathbf{n}(\%)\end{array}$ & $\begin{array}{c}<\mathbf{8} \\
\mathbf{n}(\%)\end{array}$ & $\begin{array}{c}\text { Total } \\
\mathbf{n}(\%)\end{array}$ & \\
\hline NVTA & $2(5.7)$ & $3(18.8)$ & $5(9.8)$ & 0.375 \\
IVTA & $2(5.7)$ & $0(0)$ & $2(3.9)$ & \\
FALLING & $31(88.6)$ & $13(81.3)$ & $44(86.3)$ & \\
\hline
\end{tabular}

NVTA: Non-vehicle Traffic Accident; IVTA: In-vehicle Traffic Accident.

There was no statistically significant difference between arrival GCS scores according to trauma styles ( $p>0.05$ ).

According to patient groups with an arrival, GCS score more or less than 8 , whose heavy coma limit was determined as 8, hemodynamic data, blood sugar and $\mathrm{SpO}_{2}$ averages, cardiopulmonary resuscitation (CPR) presence, pupil evaluation are summarized in Table 3. While a statistically insignificant elevation was observed in the blood glucose levels of patients whose input GCS value was below 8 , the difference seen concerning pupil reflexes was significant. The parameters evaluated according to the GCS scores at the time of exiting the intensive care unit are summarized in Table 4. There was no statistically significant difference regarding evaluated parameters of the patients with good outcome $(\mathrm{GCS} \geq 8)$ and poor outcome $(\mathrm{GCS}<8)$, but patients with good outcome were mostly patients who underwent hematoma surgery, while patients who had decompressive surgery had more severe coma, as it is summarized the table about concerning the comas. There was no statistically significant difference between forms of trauma by age and sex ( $p>0.05$ ) (Table 5).

\section{Discussion}

Follow-up and treatment of head trauma in the intensive care process are carried out according to standard head trauma protocols ${ }^{[4]}$. Accordingly, patients with $\mathrm{GCS} \geq 8$ can be checked up on under oxygen-non-invasive mechanical ventilation without intubation with close follow-up, whereas GCS $<8$ patients are treated without operation or after mechanical ventilation and sedation. It is important to protect the mechanical ventilation airway from the risk of aspiration, to avoid hypoxemia and hypercapnia, thereby avoiding the two most important factors that may cause secondary brain damage.

In our study, 51 patients, who were set for intensive care after the emergency intervention and followed-up, were analyzed. While 40 of 51 patients were intubated at the first visit to the intensive care unit, four more patients whose neurological picture worsened during their follow-up were taken to mechanical ventilation for intubation. The value put in the records as the arrival GCS score was actually taken as the first evaluation score of the patients in the

Table 3. Evaluation of the basic parameters according to the arrival GCS score

\begin{tabular}{|c|c|c|c|c|}
\hline & \multicolumn{3}{|c|}{ GCS-Arrival } & \multirow[t]{2}{*}{$\mathbf{p}$} \\
\hline & $\geq 8$ & $<8$ & Total & \\
\hline Systolic Blood Pressure $_{\text {Avg } \pm S S}$ & $141.6 \pm 27.2$ & $134.3 \pm 47.7$ & $139.3 \pm 34.6$ & 10.572 \\
\hline Heart Rate $_{\text {Avg } \pm s S}$ & $81.3 \pm 25.3$ & $88.9 \pm 23.8$ & $83.7 \pm 24.9$ & 10.321 \\
\hline Blood Sugar $_{\text {Avg } \pm S S}$ & $154.5 \pm 62.1$ & $188.8 \pm 75.9$ & $165.3 \pm 67.9$ & 10.094 \\
\hline $\mathrm{SpO}_{2 \text { Avg.tss }}$ & $96.1 \pm 2.7$ & $95.7 \pm 4.4$ & $95.9 \pm 3.3$ & 10.714 \\
\hline \multicolumn{5}{|l|}{$\mathrm{CPR}_{\mathrm{n}(\%)}$} \\
\hline Has & $1(2.9)$ & $1(6.3)$ & $2(3.9)$ & 20.533 \\
\hline Has Not & $34(97.1)$ & $15(93.8)$ & $49(96.1)$ & \\
\hline \multicolumn{5}{|l|}{ Reflex of Pupil ${ }_{n(\%)}$} \\
\hline Has Not & $1(2.9)$ & $7(43.8)$ & $8(15.7)$ & $30.001^{*}$ \\
\hline Has & $32(91.4)$ & $9(56.3)$ & $41(80.4)$ & \\
\hline Anisocoria & $2(5.7)$ & $0(0)$ & $2(3.9)$ & \\
\hline
\end{tabular}

${ }^{1}$ Student t-test; ${ }^{2}$ Fisher's Exact Test; ${ }^{3}$ Fisher Freeman Halton Test; ${ }^{*} \mathrm{p}<0.05$. 
Table 4. Evaluation according to the ICU Exit GCS score

\begin{tabular}{|c|c|c|c|c|}
\hline & \multicolumn{3}{|c|}{ GCS- ICU Exit } & $\mathbf{p}$ \\
\hline \multicolumn{5}{|l|}{ Age } \\
\hline$<65$ & $10(45.5)$ & $8(27.6)$ & $18(35.3)$ & \multirow[t]{2}{*}{10.305} \\
\hline$\geq 65$ & $12(54.5)$ & $21(72.4)$ & $33(64.7)$ & \\
\hline$<28$ & $19(86.4)$ & $22(75.9)$ & $41(80.4)$ & \multirow[t]{2}{*}{20.285} \\
\hline$>28$ & $3(13.6)$ & $7(24.1)$ & $10(19.6)$ & \\
\hline \multicolumn{5}{|l|}{ Tracheostomy } \\
\hline Has & $2(9.1)$ & $6(20.7)$ & $8(15.7)$ & \multirow[t]{2}{*}{20.440} \\
\hline Has Not & $20(90.9)$ & $23(79.3)$ & $43(84.3)$ & \\
\hline \multicolumn{5}{|l|}{ Type of Operation } \\
\hline Hematoma Surgery & 16 & 7 & 23 & \multirow[t]{2}{*}{20.320} \\
\hline Decompressive Cranialectomy & 7 & 10 & 17 & \\
\hline \multicolumn{5}{|l|}{ Antiepileptic } \\
\hline Has & $22(100)$ & $29(100)$ & $51(100)$ & - \\
\hline \multicolumn{5}{|l|}{ Mannitol } \\
\hline Has & $4(18.2)$ & $11(37.9)$ & $15(29.4)$ & \multirow[t]{2}{*}{10.221} \\
\hline Has Not & $18(81.8)$ & $18(62.1)$ & $36(70.6)$ & \\
\hline \multicolumn{5}{|l|}{ Steroid } \\
\hline Has & $12(54.5)$ & $21(72.4)$ & $33(64.7)$ & 10.305 \\
\hline
\end{tabular}

${ }^{1}$ Continuity (Yates) Correction; ${ }^{2}$ Fisher's Exact Test.

Table 5. Evaluation of the type of trauma by age and sex

\begin{tabular}{lcccc}
\hline & \multicolumn{3}{c}{ Type of Trauma } & \\
\cline { 2 - 4 } & NVTA & IVTA & FALLING & p \\
& $\mathbf{n}(\%)$ & $\mathbf{n}(\%)$ & $\mathbf{n}(\%)$ & \\
\hline Age & & & & \\
$\quad<65$ & $4(22.2)$ & $0(0)$ & $14(77.8)$ & 0.080 \\
$\geq 65$ & $1(3)$ & $2(6.1)$ & $30(90.9)$ & \\
Sex & & & & \\
$\quad \begin{array}{l}\text { Male } \\
\text { Female }\end{array}$ & $4(10)$ & $1(2.5)$ & $35(87.5)$ & 0.578 \\
\hline
\end{tabular}

Emergency Department. Thus, while there were only 16 patients with a GCS value below 8,40 patients were hospitalized as intubated. This difference arises from the total number of patients who were intubated later in the emergency unit follow-up period and who came to intensive care as intubated after the operation. After the emergency operation, according to neurological follow-up protocol, late extubation or continuation of treatment under mechanical ventilation is the treatment method in our clinic.

This study shows prognostic effects of hyperglycemia in severe head traumas. Kafaki et al. have associated blood glucose levels $>200 \mathrm{mg} / \mathrm{dl}$ with increased mortality $(>200 \mathrm{mg} /$ dl $65.8 \%,<200 \mathrm{mg} / \mathrm{dl} 23.7 \%)$ in cases of severe head injury ${ }^{[5]}$. There are similar studies showing the prognostic relationship of blood glucose levels at the time of admission in cases with head trauma ${ }^{[6,7]}$. In our patient group, $10(40.5 \%)$ of the 14 patients with a blood glucose value above $200 \mathrm{mg} / \mathrm{dl}$ was considered as the limit of hyperglycemia, and 15 (71.4\%) of the 37 patients with a blood glucose value below $200 \mathrm{mg} / \mathrm{dl}$ were lost. Intracranial pressure monitoring is the recommended monitoring in cases where an intracranial pressure increases due to possible severe head trauma. However, while ICP monitorisation through the hematoma drainage catheter can be performed in some patients, regular intracranial pressure monitoring (ICP) cannot be performed in our clinic due to 
the lack of the necessary equipment. In the patient group examined, there were no patients with an ICP follow-up.

During the follow-up of the patients, the level and duration of sedation are adjusted according to the severity of the tomographic findings (hematoma size, location, edema, shift), the state of the brain if there is an operation, the presence of intraoperative complications, the recommendations of the neurosurgical team, the results of follow-up images, and the general clinical findings of the patient. To maintain the average arterial brain pressure and the perfusion- pressure, which is important for the brain tissue, it is monitored by invasive artery monitoring, and the blood gas, glucose, electrolytes and fluid management are kept under close monitoring. Vasoconstrictive drug treatments are used for fluid restriction strategy and, if necessary, to increase the average of arterial pressures. The patient is regularly monitored for neurological findings and takes other necessary supportive treatments (nutrition, position, prevention measures from nosocomial infections) during the intensive care process.

If there is no complication amongst patients with GCS $>8$ and has a good clinical course, intensive care follow-up times are generally shorter and these patients are transferred to the $1^{\text {st }}$ level care unit in the Neurosurgery clinic for rehabilitation in a short time.

Emergency surgery was approved in 40 of 51 patients and all took place within the first 24 hours. While 16 patients undergoing hematoma surgery had good results (GCS $\geq 8$ ), seven patients had poor results (GCS $<8$ ), seven patients undergoing decompressive craniectomy had good results (GCS $\geq 8), 10$ patients had poor results (GCS $<8$ ). When 17 patients with poor outcomes were further evaluated, eight of these patients had lower than 8 GCS scores upon arrival, and these patients were exposed to multiple intracranial pathologies (acute subdural hematoma, subarachnoid hemorrhage, contusion, epidural bleeding) and multiple body traumas along with the severe head trauma.

When the intensive care hospitalization times are analyzed, there is no statistical difference between the duration of hospitalization of patients admitted to the emergency admission GCS score below and above 8. Apart from patients with head injuries, patients who were lost early due to severe multiple trauma or brain death or patients whose life-threatening cranial or other systemic causes disappear within a few days and are not deemed unfit to be transported to service care the rate generally points to a long intensive care admission. In our study, although the average duration of hospitalization was longer in the group with a
GCS score below 8, the lack of statistical difference could be explained as the early losses seen in the severe trauma group, and therefore, the effects of the short duration of stay on the average time. In this group, the duration of hospitalization of four patients is less than six days. Patients with an arrival GCS score below eight, and have stayed longer than 28 days have had surgical intervention.

Decompressive craniectomy, which is the last step of the treatment in refractory intracranial pressure increases, is not recommended because of the complications of this procedure and the controversial results ${ }^{[8-10]}$. While decompressive craniectomy prolongs life in patients with a severe coma outcome, it often does not provide a significant improvement in the patients' coma scores upon their exits. Out of the 11 patients who were operated in our patient group, whose GSC scores were below 8, only four of the seven patients lying longer than seven days had an outflow scoreHyperosmolar treatments remain as a therapeutic option in intracranial hypertension. The intracranial pressure-reducing effect of mannitol is thought to reduce direct brain edema ${ }^{[11]}$.

Applying hyperosmolar treatment as early as possible, within 24 hours, may have positive effects on treatment ${ }^{[12]}$. In our hospital for cases thought to have intracranial hypertension, mannitol is routinely applied in the first hours, and it is discontinued by decreasing it for one week -10 days according to the clinical course.

Post-traumatic seizures (PTS) can be seen early (after the first seven days of the trauma) and late (after the $7^{\text {th }}$ day after the trauma) after traumatic brain injury, and have the potential to induce secondary injury and post-traumatic epilepsy in the traumatic brain. Thus, the use of prophylactic antiepileptic drugs in patients with traumatic brain injury is recommended, albeit controversial ${ }^{[13,14]}$. This practice has been adopted by the appropriate clinics of our hospital, and antiepileptic treatment is routinely added to the treatment in cases where brain damage is predicted to occur.

Although corticosteroid use is a controversial medical treatment method, recent meta-analyses are interpreted as an advantage in antiedema treatment in the circumstances accompanied by edema ${ }^{[15]}$. In our clinic, corticosteroids are preferred to be added to the treatment accompanied by cerebral edema and are reduced and discontinued after a week or 10-day treatment period. Tracheotomy applications are planned in patients who are unable to protect the airway, need respiratory support and patients whose circumstances are expected to take a long time and follow the general intensive care principles. It is usually applied on the $15^{\text {th }}$ day, 
sometimes earlier or later than the patient's clinic.

In our study, the intensive care 28-day mortality rate was $46.4 \%$. After intensive care, their stay in the service varied between 0-69 days.

\section{Conclusion}

In traumatic brain injuries, in order to prevent the secondary damage following the primary one, each center should make sure that they are aware of their functioning, they should perform their patient analysis and identify their high risk group of patients.

Ethics Committee Approval: Retrospective study.

Peer-review: Externally peer-reviewed.

Authorship Contributions: Concept: M.E.; Design: M.E.; Data Collection or Processing: S.A.K.; Analysis or Interpretation: A.Ö.; Literature Search: A.Ö.; Writing: A.Ö.

Conflict of Interest: None declared.

Financial Disclosure: The authors declared that this study received no fina ncial support.

\section{References}

1. Saatian M, Ahmadpoor J, Mohammadi Y, Mazloumi E. Epidemiology and Pattern of Traumatic Brain Injury in a Developing Country Regional Trauma Center. Bull Emerg Trauma 2018;6:45-53. [CrossRef]

2. Stocker RA. Intensive Care in Traumatic Brain Injury Including Multi-Modal Monitoring and Neuroprotection. Med Sci (Basel) 2019;7. [CrossRef]

3. Kim AK, Moonis G, Loeyner LA. Brain: Anatomy, Trauma, and Tumors, Chapter 48 In: Pretorius E, Solomon J, (editors). Radiology Secrets Plus. 3rd ed. Mosby, 2011: 327-35. [CrossRef]

4. Asehnoune K, Roquilly A, Cinotti R. Respiratory Management in Patients with Severe Brain Injury. Crit Care 2018;22:76.
5. Kafaki SB, Alaedini K, Qorbani A, Asadian L, Haddadi K. Hyperglycemia: A Predictor of Death in Severe Head Injury Patients. Clin Med Insights Endocrinol Diabetes 2016;9:43-6. [CrossRef]

6. Young B, Ott L, Dempsey R, Haack D, Tibbs P. Relationship between admission hyperglycemia and neurologic outcome of severely brain-injured patients. Ann Surg 1989;210:466-73.

7. Yang SY, Zhang S, Wang ML. Clinical significance of admission hyperglycemia and factors related to it in patients with acute severe head injury. Surg Neurol 1995;44:373-7. [CrossRef]

8. Sahuquillo J, Arikan F. Decompressive craniectomy for the treatment of refractory high intracranial pressure in traumatic brain injury. Cochrane Database Syst Rev 2006;(1):CD003983.

9. Cooper DJ, Rosenfeld JV, Murray L, Arabi YM, Davies AR, D'Urso $P$, et al; DECRA Trial Investigators; Australian and New Zealand Intensive Care Society Clinical Trials Group. Decompressive craniectomy in diffuse traumatic brain injury. $\mathrm{N}$ Engl J Med 2011;364:1493-502. [CrossRef]

10. Stiver SI. Complications of decompressive craniectomy for traumatic brain injury. Neurosurg Focus 2009;26:E7. [CrossRef]

11. Diringer MN, Scalfani MT, Zazulia AR, Videen TO, Dhar R, Powers WJ. Effect of Mannitol on Cerebral Blood Volume in Patients with Head Injury. Neurosurgery 2012;70:1215-8.

12. Johnson M. Rich R. Cochran S. 1770: Timing of the first dose of hyperosmolar therapy following severe traumatic brain injury. Critical Care Medicine 2019;47:858. [CrossRef]

13. Chartrain AG, Yaeger K, Feng R, Themistocleous MS, Dangayach NS, Margetis K, et al. Antiepileptics for Post-Traumatic Seizure Prophylaxis after Traumatic Brain Injury. Curr Pharm Des 2017;23:6428-41. [CrossRef]

14. Wat R, Mammi M, Paredes J, Haines J, Alasmari M, Liew A, et al. The Effectiveness of Antiepileptic Medications as Prophylaxis of Early Seizure in Patients with Traumatic Brain Injury Compared with Placebo or No Treatment: A Systematic Review and Meta-Analysis. World Neurosurg 2019;122:433-40. [CrossRef]

15. Beez T, Steiger HJ, Etminan N. Pharmacological targeting of secondary brain damage following ischemic or hemorrhagic stroke, traumatic brain injury, and bacterial meningitis - a systematic review and meta-analysis. BMC Neurol 2017;17:209. 